\title{
A novel minimally invasive off-pump biventricular assist device insertion technique
}

Zain Khalpey, MD, PhD, Richard Smith, MSEE, Angela Echeverria, MD, Phat le Tran, PhD, and Toshinobu Kazui, MD, PhD, Tucson, Ariz

From the Division of Cardiothoracic Surgery, Banner University Medical Center-Tucson, Tucson, Ariz. Disclosures: Authors have nothing to disclose with regard to commercial support.

Received for publication April 15, 2015; revisions received June 8, 2015; accepted for publication July 24, 2015; available ahead of print Aug 28, 2015.

Address for reprints: Zain Khalpey, MD, PhD, Division of Cardiothoracic Surgery, The University of Arizona Medical Center, 1501 N Campbell Ave, Room 4302A, PO Box 245071, Tucson, AZ 85724-5071 (E-mail: zkhalpey@surgery.arizona.edu).

J Thorac Cardiovasc Surg 2016;151:e5-7

$0022-5223 / \$ 36.00$

Copyright (C) 2016 by The American Association for Thoracic Surgery

http://dx.doi.org/10.1016/j.jtcvs.2015.07.074

Biventricular assist device (BIVAD) insertion is a feasible and preferable surgical treatment option for refractory cardiogenic shock. ${ }^{1,2}$ Cardiopulmonary bypass through a median sternotomy in a patient with failing (Interagency Registry for Mechanically Assisted Circulatory Support level 1) circulation can induce profound coagulopathy and systemic inflammation, necessitating multiple blood transfusions and leading to potential antibody development. ${ }^{1}$ Minimizing surgical trauma and allowing early postoperative ambulation may optimize outcomes in these patients. We describe the first 3 patients performed

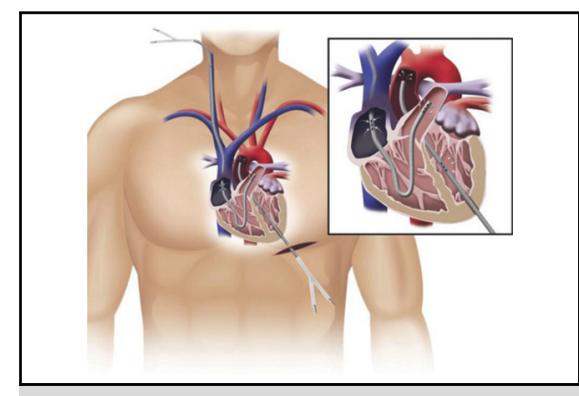

Left and right ventricular assist devices.

Central Message

We describe the first case of a patient treated successfully with a minimally invasive offpump biventricular assist device insertion.

See Editorial Commentary page e9.

successfully with minimally invasive off-pump BIVAD insertion for bridge to decision.

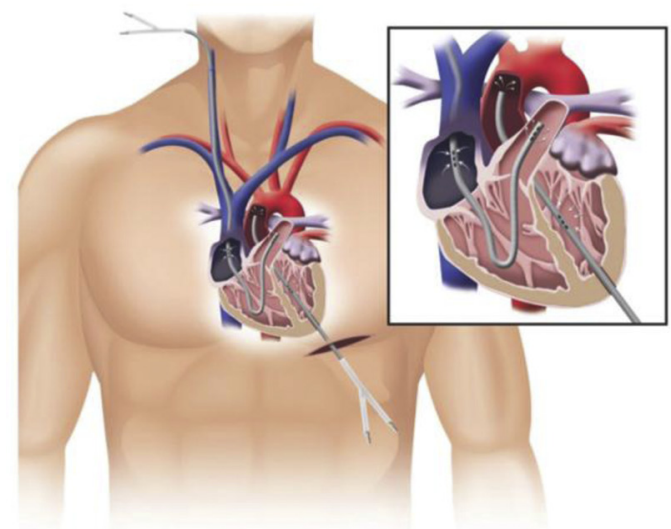

A

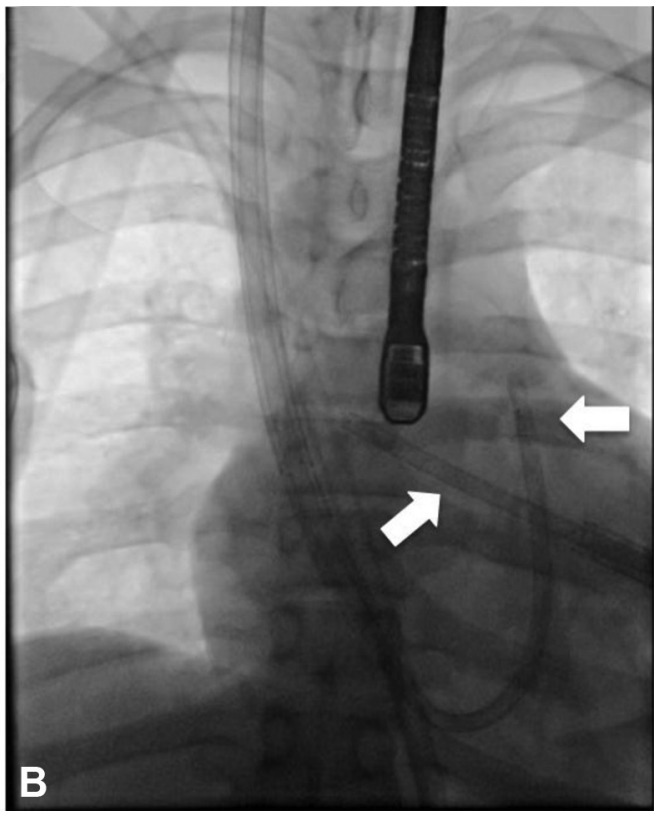

FIGURE 1. Graphic illustration (A) and intraoperative radiograph (B) of biventricular cannulation. The tip of cannula on the left side was cut at the back table. Left ventricular assist device inflow was placed in the left ventricle, and outflow was placed in the ascending aorta. Right ventricular assist device inflow was placed in the right atrium, and outflow was placed in the main pulmonary artery. The tips of the left ventricular assist device cannula and right ventricular assist device cannulas are indicated by arrows. 
TABLE 1. Snapshot of 3 cases of minimally invasive off-pump biventricular assist device placement

\begin{tabular}{|c|c|c|c|}
\hline & Patient 1 & Patient 2 & Patient 3 \\
\hline Age (y) & 22 & 46 & 64 \\
\hline Sex & Male & Male & Male \\
\hline Etiology & NICM & $\mathrm{ICM}$ & ICM \\
\hline Ejection fraction $(\%)$ & 10 & 15 & 10 \\
\hline INTERMACS level & 2 & 1 & 1 \\
\hline Preoperative device support & - & Impella CP & IABP \\
\hline Operative time (min) & 202 & 152 & 100 \\
\hline Intraoperative blood loss (mL) & $<250$ & $<250$ & $<250$ \\
\hline $\begin{array}{l}\text { Intraoperative blood } \\
\text { transfusion (units) }\end{array}$ & 0 & 0 & 0 \\
\hline $\begin{array}{l}\text { Postoperative blood } \\
\text { transfusion (units) }\end{array}$ & 0 & 8 & 7 \\
\hline \multicolumn{4}{|l|}{ Cardiac rhythm (beats/min) } \\
\hline Preoperative & ST, $140-150$ & ST, 126 & ST, 133 \\
\hline Postoperative & NSR, 95 & NSR, 55 & NSR, 90 \\
\hline \multicolumn{4}{|l|}{ Mixed venous saturation $(\%)$} \\
\hline Preoperative & $50 \%$ & - & $38 \%$ \\
\hline Postoperative & $71 \%$ & - & $60 \%$ \\
\hline \multicolumn{4}{|l|}{ Lactate (IU/L) } \\
\hline Preoperative & 2.8 & 7.3 & 2.2 \\
\hline Postoperative & 1.5 & 1.6 & 1.3 \\
\hline \multicolumn{4}{|l|}{ Mitral regurgitation } \\
\hline Preoperative & Severe & Mild & Mild \\
\hline Postoperative & Mild & Mild & Mild \\
\hline \multicolumn{4}{|l|}{ Aortic insufficiency } \\
\hline Preoperative & Mild & Trivial & Trivial \\
\hline Postoperative & Mild & None & Trivial \\
\hline RVAD removal (POD) & 9 & 4 & 8 \\
\hline LVAD removal (POD) & 10 & 6 & 15 \\
\hline Result & $\begin{array}{l}\text { Bridged to } \\
\text { implantable } \\
\text { device }\end{array}$ & $\begin{array}{c}\text { Weaned from } \\
\text { the device }\end{array}$ & Deceased \\
\hline
\end{tabular}

NICM, Nonischemic cardiomyopathy; ICM, ischemic cardiomyopathy; INTER$M A C S$, Interagency Registry for Mechanically Assisted Circulatory Support; IABP, intra-aortic balloon pump; $S T$, sinus tachycardia; NSR, normal sinus rhythm; $R V A D$, right ventricular assist device; $P O D$, postoperative day; $L V A D$, left ventricular assist device.

\section{CLINICAL SUMMARIES Patient 1}

A 22-year-old man with acute decompensated congestive biventricular heart failure as a result of nonischemic cardiomyopathy with an ejection fraction of $15 \%$ and a normal cardiac catheterization presents with a 7-day history of flulike symptoms. Radiography and computed tomographic scan demonstrated pneumonia $(30,000$ white blood cells $/ \mu \mathrm{L}$ ) with refractory cardiogenic shock and increasing vasopressor support. As a temporary bridge to implantable devices, a minimally invasive BIVAD system (CentriMag; Thoratec Corporation, Pleasanton, Calif), was placed because of his fever of unknown origin.
The left ventricular apex position was confirmed by means of transesophageal echocardiography. A $5-\mathrm{cm}$ 5th left minithoracotomy incision was performed. A pericardial well was created with systemic heparinization. Two 3-0 pledgeted Prolene purse-string sutures (Ethicon, Inc, Somerville, NJ) were placed around the left ventricular apex. A 29Fr PROTEK Duo cannula (CardiacAssist, Inc, Pittsburgh, Pa) was cut $10.5 \mathrm{~cm}$ shorter at the distal end, resulting in a single port with $7 \mathrm{~cm}$ in length, so the tip wouldn't migrate into neck vessels while crossing the aortic valve. It was placed with Seldinger technique under transesophageal echocardiography guidance and fluoroscopy. The cannula was connected to the CentriMag left ventricular assist device (LVAD).

With the Swan-Ganz catheter in position, a guidewire was passed over into the right pulmonary artery under fluoroscopy. The Swan-Ganz catheter was removed, and the 29Fr PROTEK Duo cannula was inserted. The position of the cannula tip in the pulmonary artery was confirmed with fluoroscopy. The cannula was connected to the CentriMag right ventricular assist device (RVAD). The RVAD and LVAD were titrated to $3.5 \mathrm{~L} / \mathrm{min}$ and $4.0 \mathrm{~L} / \mathrm{min}$, respectively, under transesophageal echocardiographic guidance (Figure 1).

Hemostasis was achieved with an activated clotting time goal of 180 to 220 seconds, and the incision was closed.

The patient was extubated and ambulated on postoperative day (POD) 2, and inotropes were tapered. No transfusion was required. On POD 10, the CentriMag BIVAD was switched to HVAD (HeartWare, Framingham, Mass) due to fibrin strands by the connector and CentriMag RVAD as a bridge to transplant. On POD 34, the HVAD and the CentriMag devices were removed and replaced with a 50-mL TAH (SynCardia Systems, Inc, Tucson, Ariz) for bridge to transplant on the basis of RVAD weaning failure despite extensive fluid removal during the BIVAD support. The patient is in status 1B awaiting heart transplant (Table 1).

\section{Patient 2}

A 46-year-old man with ischemic cardiomyopathy (left ventricular ejection fraction of $10 \%$ ) had stents placed in his left anterior descending and circumflex coronary arteries with Impella support (Abiomed, Inc, Danvers, Mass). Despite this, his hemodynamics were compromised by numerous ventricular tachycardia and ventricular fibrillation episodes. The patient underwent off-pump BIVAD placement as described previously with RVAD flow of $4.0 \mathrm{~L} / \mathrm{min}$ and LVAD flow of $4.6 \mathrm{~L} / \mathrm{min}$. His ejection fraction improved to $25 \%$. His RVAD and LVAD support were discontinued on PODs 4 and 6, respectively (Table 1). Patient was 
discharged to a rehabilitation center without any inotropes support.

\section{Patient 3}

A 63-year-old man was seen with a new left ventricular anterior wall ST-segment elevation myocardial infarction. An intra-aortic balloon pump was placed, and he was intubated for pulmonary edema and renal failure. Because of his unstable hemodynamics and general status, he underwent off-pump LVAD placement (3.9 $\mathrm{L} / \mathrm{min})$ as described previously for bridge to decision. He had multiple ventricular tachycardia and ventricular fibrillation episodes after the LVAD placement, and RVAD support $(3.1 \mathrm{~L} / \mathrm{min})$ was initiated on POD 5. His RVAD was weaned on POD 13; however, his general status did not recover, and his family withdrew care on POD 19 (Table 1).

\section{DISCUSSION}

To our best knowledge, this is the first report of a novel technique for a minimally invasive off-pump BIVAD placement. In 3 patients with cardiogenic shock, the PROTEK Duo Cannulas was conveniently and effectively used as a bridge to a durable implantable device, explant, or decision.

There are many advantages of off-pump BIVAD placement relative to the conventional median sternotomy BIVAD placement. CentriMags are a reliable temporary pump, ${ }^{3}$ and this off-pump procedure can be performed in a short time frame $(<3$ hours), minimizing blood loss, transfusion, and postoperative inflammation. Furthermore, avoiding a median sternotomy preserves the sternum for a later chest reentry for a durable implantable device or heart transplant. Patients can be extubated early and can ambulate early postoperatively without any groin instrumentation or cannulation; this provides an advantage relative to previously reported percutaneous RVAD insertion. ${ }^{4}$ In contrast with conventional BIVAD configuration, ${ }^{1,5}$ a patient needs only 2 cannula sites to establish BIVAD support with the PROTEK Duo dual-lumen cannula. Because of its simplicity, the rate of peripheral ECMO use can potentially be reduced. Central cannulation will eliminate ischemic leg complications and robustly decompress ventricles, allowing ventricular recovery and decreased clot formation because of the constant flow through the ventricles.

Traditional sternal reentry under emergency conditions is treacherous and cumbersome. This procedure has great utility in patients with previous cardiac surgery. The procedure makes it technically easy to establish BIVAD support and provides efficient support and decompression in cardiogenic shock in coagulopathic patients. The disadvantage of having only a single cannula size limits patients with a larger body surface area; however, the cannula is being redesigned shorter and larger (personal communication, Kevin Rollins, May 2015) for LVAD use, and it is safe and feasible.

\section{References}

1. Takayama H, Soni L, Kalesan B, Truby LK, Ota T, Cedola S, et al. Bridge-to-decision therapy with a continuous-flow external ventricular assist device in refractory cardiogenic shock of various causes. Circ Heart Fail. 2014;7:799-806.

2. Aissaoui N, Morshuis M, Paluszkiewicz L, Lauenroth V, Borgermann J, Gummert J. Comparison of biventricular and left ventricular assist devices for the management of severe right ventricular dysfunction in patients with endstage heart failure. ASAIO J. 2014;60(4):400-6.

3. John R, Long JW, Massey HT, Griffith BP, Sun BC, Tector AJ, et al. Outcomes of a multicenter trial of the Levitronix Centrimag ventricular assist system for shortterm circulatory support. J Thorac Cardiovasc Surg. 2011;141:932-9.

4. Takayama H, Naka Y, Kodali SK, Vincent JA, Addonizio LJ, Jorde UP, et al. A novel approach to percutaneous right-ventricular mechanical support. Eur J Cardiothorac Surg. 2012;41:423-6.

5. Borisenko O, Wylie G, Payne J, Bjessmo S, Smith J, Yonan N, et al. Thoratec Centrimag for temporary treatment of refractory cardiogenic shock or severe cardiopulmonary insufficiency: a systematic literature review and meta-analysis of observational studies. ASAIO J. 2014;60:487-97. 